Portland State University

PDXScholar

\title{
Understanding Multidigit Whole Numbers: The Role of Knowledge Components, Connections, and Context in Understanding Regrouping 3+-Digit Numbers
}

Eva Thanheiser

Portland State University, evat@pdx.edu

Follow this and additional works at: https://pdxscholar.library.pdx.edu/mth_fac

Part of the Science and Mathematics Education Commons

Let us know how access to this document benefits you.

\section{Citation Details}

Published as: Eva Thanheiser (2012). Understanding multidigit whole numbers: The role of knowledge components, connections, and context in understanding regrouping 3+-digit numbers, The Journal of Mathematical Behavior, Volume 31, Issue 2, Pages 220-234.

This Post-Print is brought to you for free and open access. It has been accepted for inclusion in Mathematics and Statistics Faculty Publications and Presentations by an authorized administrator of PDXScholar. Please contact us if we can make this document more accessible: pdxscholar@pdx.edu. 


\title{
Understanding Multidigit Whole Numbers: The Role of Knowledge Components, Connections, and Context in Understanding Regrouping 3+-Digit Numbers
}

Eva Thanheiser

\section{Portland State University}

Acknowledgements: I would like to thank Chad Bemis, Jason Dolor, Estrella Johnson, Carolyn McCaffrey, Briana Mills, Sonya Redmond, Krista Strand, and Steve Strand, who analyzed parts of the transcript as a class project and engaged in discussions with me about this case. I would also like to thank the editor and the anonymous reviewers for excellent feedback on prior drafts of this manuscript as well as Bonnie Schappelle without whom this article would not read as well as it does.

\begin{abstract}
This case study of a PST's understanding of regrouping with multidigit whole numbers in base10 and non-base-10 contexts shows that although she seems to have all the knowledge elements necessary to give a conceptually based explanation of regrouping in the context of 3-digit numbers, she is unable to do so. This inability may be due to a lack of connections among various knowledge components (conceptual knowledge) or a lack of connections between knowledge components and context (strategic knowledge). Although she exhibited both conceptual and strategic knowledge of numbers while regrouping 2-digit numbers, her struggles in explaining regrouping 3-digit numbers in the context of the standard algorithms indicate that explaining regrouping with 3-digit is not a mere extension of doing so for 2-digit numbers. She also accepts an overgeneralization of the standard algorithms for subtraction to a time (mixed-
\end{abstract}


base) context, indicating a lack of recognition of the connections between the base-10 contexts and the standard algorithms. Implications for instruction are discussed.

Consider subtracting $23-7$ using the standard regrouping algorithm used in the United States. To do so, one would regroup 1 ten into 10 ones (see Figures 1a and 1b), this regrouping is correct because the value of the regrouped digit stays the same; however, the reference unit of the digit changes: one ten is reconceived as 10 ones. Thus, to explain the mathematics underlying this regrouping, one would need to know the following: (a) that the 2 represents 2 tens (or 20) and the 3 represents 3 ones; (b) that 1 ten can be reconceived as 10 ones (or know that 20 can be separated into 10 and 10); and (c) that 10 ones can be moved from the ten's place to the one's place and combined with the 3 ones already there.

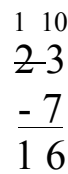

Figure 1a. Subtracting $23-7$ using the standard algorithm.
Figure $1 b$. One PST's regrouping in the context of $23-7$.

Preservice teachers (PSTs) struggle explaining the value of regrouped digits in the context of addition and subtraction (Ball, 1988; Ma, 1999; Southwell \& Penglase, 2005; Thanheiser, 2009), and although some PSTs may interpret digits correctly at some times, they may interpret digits incorrectly at others (Thanheiser, 2009, 2010). Research results indicating that adults have trouble understanding and explaining digits in a number are often met with surprise and sometimes with disbelief. The reader may share this disbelief because after one understands the topic of whole numbers and regrouping, he or she may be unable to imagine not 
having this understanding. In previous work (Thanheiser, 2009, 2010), I have demonstrated the complexities inherent in explaining the values of the regrouped digits in the context of addition and subtraction (a review follows below). In this paper, I focus on examining the connections between various types of knowledge, namely procedural, conceptual (cp. Hiebert \& Lefevre, 1986), and strategic (cp. Weber, 2001) knowledge. More specifically, I examine whether knowing the individual components of knowledge needed to explain a concept such as regrouping (as described above) enables one to explain that concept and how knowledge of a concept relates to understanding in what situations it is applicable.

\section{Background}

Research to date has shown that children as well as teachers and PSTs struggle understanding numbers. Children struggle when learning about number and the numeration system. Only $60 \%$ of U.S. $8^{\text {th }}$ graders were able to write a 3 -digit number when given digits and conditions related to their place values (Kouba \& Wearne, 2000). And only about half the children in fourth grade understand that the 1 in 16 represents 10 (Kamii, 1986; Ross, 1990a). Children often build juxtaposed and unrelated systems of ones and tens (Cobb \& Wheatley, 1988; Kamii, 1986; Ross, 1990a) and, thus, struggle to relate tens and ones. For these children, tens and ones are just different unit types: "Ten was, for them, one thing which was not itself composed of units" (Cobb \& Wheatley, 1988, p. 1). These children, therefore, struggle to understand numbers because they do not understand the basic relationships among the digits in the number. To understand 2-digit numbers, students must relate tens and ones (Fuson et al., 1997; Kamii, 1986).

When children learn the standard algorithms, they are often drilled on the procedures, and many fail to construct meaning for the algorithms. Learning procedures without understanding 
can be detrimental to children (Ball, 1988; Kamii, 1986). Children learn where to write the digits but might not understand why when they add 7 and 5, for example, they write the 2 below and regroup the 1 to the next column. Without constructing meaning for the algorithms, children might concentrate more on the rules of the algorithm than on "the essence of the numeration system — the numerals have different values depending on their place" (Ball, 1988, p. 49).

To summarize, children struggle understanding multidigit whole numbers, and although they may be able to apply procedures, they are unlikely to be able to explain the underlying mathematics or why the procedures are applicable in a context. For children to form a conceptual and strategic understanding of mathematics rather than to develop only procedural skills, they need to be taught in a way that helps them construct meaning and connect that meaning to contexts. To construct meaning for most mathematical concepts, children need to have a conceptual understanding of number and need to be able to draw on that knowledge in appropriate contexts (strategic knowledge). To guide students toward such an understanding of number, teachers, in turn, need a profound understanding (Ma, 1999) of number.

Teachers and PSTs also struggle with understanding numbers. PSTs can perform algorithms but struggle when asked to explain them (Ball, 1988; Ma, 1999; Southwell \& Penglase, 2005; Thanheiser, 2009, 2010). Although the PSTs are able to execute the procedures, they often do so by merely manipulating algorithms (McClain, 2003; Tirosh \& Graeber, 1989).

Several researchers have focused on various aspects of PSTs' understanding of numbers: number sense (Graeber, 1989; Huang, 2009), alternative algorithms (Luo, 2009), and number concepts (Southwell \& Penglase, 2005). These researchers have shown that PSTs tend to focus on procedures and that place value seems to cause the most difficulty for PSTs. 
Because PSTs are usually satisfied with their own procedural understandings (until they are asked to explain the underlying mathematics), they are likely to take their own procedural fluency as evidence of conceptual understanding (Graeber, 1999). One PST reflected,

I remember feeling very frustrated [when asked why regrouping works in the context of addition and subtraction] because I couldn't explain how I solved the addition and subtraction problems. To me, those kinds of problems you just solved. I don't remember ever having to explain why I did a certain step or math procedure. (PST in elementary mathematics methods course)

Procedural fluency will not, however, prepare PSTs to teach in a way that fosters conceptual understanding or strategic knowledge in the children they teach.

The issue of the kinds of knowledge teachers need to teach with a focus on developing sense making and conceptual understanding has been the focus of much research in the mathematics education community (e.g. Hill, Ball \& Schilling, 2008; Hill, Rowan \& Ball, 2005; Ma, 1999; National Research Council, 2001; Shulman, 1986; Silverman \& Thompson, 2008) and has resulted in various frameworks describing mathematical knowledge for teaching. All descriptions/frameworks include mathematical content knowledge as part (or center) of the frameworks. A consensus seems to exist that mathematical content knowledge is an essential aspect (if not the core of) mathematical knowledge for teaching and that this content knowledge needs to be deeply held (Ma, 1999) and multifaceted (Hill et al., 2008) In addition, teachers and PSTs must be able to decide when to draw on a mathematics concept.

Thus, researchers of children's and PSTs' content knowledge have (a) shown that understanding multidigit numbers is difficult and (b) put forth frameworks for children's (Fuson et al., 1997) and PSTs' (Thanheiser, 2009) conceptions (correct and incorrect) of multidigit whole numbers, laying out various components of conceptual knowledge one needs to explain regrouping, However, an open question is whether knowing the components essential in a correct conception 
enables one to (a) provide a correct explanation and (b) recognize when concepts are applicable (and when they are not). Those issues are the foci of the current study.

In the next sections, I discuss aspects essential to PSTs' content knowledge of a mathematical concept: (a) the constructs of conceptual and procedural understanding, in general, (b) the knowledge of whole numbers essential for explaining conceptually the regrouping in the standard algorithms for addition and subtraction, (c) strategic knowledge-how to decide when a concept/procedure is useful in a situation, and (d) transfer - how to decide in what contexts a concept/procedure is valid and how to adapt the concept/procedure to a new situation.

\section{Conceptual versus procedural knowledge}

The distinctions among types of understanding/knowledge date back to Skemp (1978), who initially distinguished relational and instrumental understanding, defining relational understanding as "knowing both what to do and why" (p. 21) and instrumental understanding as "rules without reason" (p. 21). Hiebert and Lefevre (1986) distinguished conceptual and procedural knowledge, defining conceptual knowledge as

Knowledge that is rich in relationships. It can be thought of as a connected web of knowledge, a network in which the linking relationships are as prominent as the discrete pieces of information. Relationships pervade the individual facts and proposition so that all pieces of information are linked to some network. (pp. 3-4)

and procedural knowledge as twofold: (a) "familiarity with the individual symbols of the system and with the syntactic conventions for acceptable configurations of symbols," (p. 7) and (b) "rules or procedures for solving mathematical problems" (p. 7). Thompson, Philipp, Thompson, and Boyd (1994) distinguished between calculational and conceptual orientations for teaching. “Conceptually oriented teachers ... focus students' attention away from the thoughtless application of procedures towards a rich conception of situations, ideas, and relationships among 
ideas" (p. 86). Such teachers are contrasted with teachers who have a calculational orientation and are driven by "the application of calculations and procedures for deriving numerical results." (p. 86).

In the distinctions among types of understanding (Skemp, 1978), knowledge (Hiebert \& Lefevre, 1986), and orientation toward teaching (Thompson et al., 1994), two sides emerge: one focused on a richly connected understanding of the mathematics underlying procedures and one focused on applying procedures. Star (2005) raised a distinction between the two types of knowledge/understanding/orientation. Although the first (relational understanding, conceptual knowledge, conceptually oriented teaching) encompasses two characteristics, a focus on what is known (concepts) as well as on how it is known (richly connected), the second (instrumental understanding, procedural knowledge, calculational oriented teaching) seems to focus only on what is known (procedures).

Baroody et al. (2007), in their response to Star (2005), summarized research of mathematics education researchers. They illustrated two additional concepts. In addition to procedural knowledge, they characterized deep procedural knowledge as "well-connected, contextualized, integrated, meaningful, general, or strategic" (p. 117). In addition to conceptual knowledge, they characterized superficial conceptual knowledge as "sparsely connected" (p. 117). Combining superficial conceptual knowledge with procedural knowledge, they defined routine expertise as "knowledge that can be applied effectively to familiar but not new tasks" (p. 117). Combining deep conceptual and deep procedural knowledge they, drawing on Hatano (Hatano, 1988, 2003) and many other mathematics education researchers, defined adaptive expertise as "meaningful knowledge that can be applied creatively, flexibly, and appropriately to new, as well as familiar tasks" (p. 117). 
In this paper, I examine the role of connections in conceptual understanding of multidigit whole numbers: If a PST has all the conceptual components necessary to explain the mathematics of the algorithms, will this PST be poised to do so? To address this question, I first examine these components of conceptual knowledge in the next sections.

\section{What knowledge components does one need to give a conceptual explanation of the standard algorithms for addition and subtraction?}

In previous work (Thanheiser, 2009), I identified PSTs' conceptions of multidigit whole numbers when they enter their mathematics courses for teachers and categorized them into four major groups: thinking in terms of (1) reference units, (2) groups of ones, (3) concatenated-digits plus, and (4) concatenated-digits only.

1. Reference units. PSTs with this conception reliably ${ }^{1}$ conceive of the reference units for each digit and relate reference units to one another, seeing the 3 in 389 as 3 hundreds or 30 tens or 300 ones, the 8 as 8 tens or 80 ones, and the 9 as 9 ones. They can reconceive of 1 hundred as 10 tens, and so on.

2. Groups of ones. PSTs with this conception reliably conceive of all digits in terms of groups of ones ( 389 as 300 ones, 80 ones, and 9 ones) but not in terms of reference units; they do not relate reference units (e.g., 10 tens to 1 hundred).

3. Concatenated-digits plus. PSTs with this conception conceive of at least one digit as an incorrect unit type at least sometimes. They struggle when relating values of the digits to one another (e.g., in 389,3 is 300 ones but the 8 is only 8 ones).

\footnotetext{
${ }^{1}$ Reliably in these definitions means that after the PSTs were first able to draw on a conception in their explanations in a context, they continued to do so in that context.
} 
4. Concatenated-digits only. PSTs holding this conception conceive of all digits in terms of ones (e.g., 548 as 5 ones, 4 ones, and 8 ones).

I give a brief example of how PSTs with each of the above conceptions may explain regrouping/the value of the regrouped digits in the context of 527 - 135 (see Figure 1). (For an in-depth explanation, please see (Thanheiser, 2009, 2010).

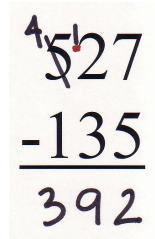

Figure 1. Standard-algorithm solution to 527-135.

A PST with a reference-units conception might explain regrouping/the-value-of-theregrouped-digits by relating the value of a hundred to 1 hundred, 10 tens, and 100 ones. One PST in this category explained "[the value of the regrouped digits in the hundred's place is] 4 hundreds ... the hundreds is the same as 10 tens, okay [thus the value of the 12 in the ten's place], 12 tens. is the same as 120 ... I changed it [the hundred] into 10 tens." This PST saw a hundred as 1 hundred she took from the hundred's place, 10 tens she added to the ten's place, and 100 ones when interpreting the value of the 12 as 120 .

A PST with a groups-of-ones conception might explain regrouping/the-value-of-theregrouped-digits by shifting 100 from the hundred's place to the ten's place but struggle relating the 12 in the ten's place to its value (120). One PST in this category explained, "So the 5[00] becomes 400 and this is, the 2 is actually 20, and you add 100 and it becomes $120 \ldots$ this [12 in the ten's place] becomes 120, but I don't know why it is that you don't see the 0 [of the 120]; I don't know, I don't know why you don't see that 0. .” 
A PST with a concatenated-digits-plus conception might explain regrouping/the-value-ofthe-regrouped-digits by recognizing that she is taking 100 from the 500 but may be unable to explain where that 100 goes because she sees the regrouped digit in the ten's place as 10 . One PST in this category explained, "You'd have 500, and then if you are taking out one, it's 1 hundred. But that [the regrouped 1 in $4^{1} 27$ ] is only 10 , and you actually have one hundred; like [pause], I don't know how to explain this one."

A PST with a concatenated-digits-only conception might explain regrouping/the-valueof-the-regrouped-digits by simply shifting a 1 over and putting it in the ten's place beside the 2 but still consider it to be a 1 . One PST in this category explained. "A 1 is taken away from it, but it's put in the ten's place for the next number ... the 2 became a 12 but the 1 was added on to it, was put in front of it"

Of the 15 participants in that study, 3 held concatenated-digits-only conceptions, 7 concatenated-digits-plus conceptions, 2 groups-of-ones conceptions, and 3 reference-units conceptions (see Table 1). Similar results were found in a larger studies (R. A. Philipp, personal communication, September 4th, 2007; Thanheiser, 2010).

Table 1

Distribution of Conceptions in the Context of the Standard Algorithm for the 15 PSTs in the Study

\begin{tabular}{lc}
\hline \multicolumn{1}{c}{ Conception held } & \# of PSTs \\
\hline Reference units & 3 \\
Groups of ones & 2 \\
Concatenated-digits plus & 7 \\
Concatenated-digits only & 3 \\
\hline
\end{tabular}


Thus, two thirds of the PSTs interviewed held either a concatenated-digits-plus or a concatenated-digits-only conception (see Table 1). Inasmuch as these PSTs see the value of a digit incorrectly at least some of the time, it is unsurprising that they struggled in explaining regrouping in the addition and subtraction algorithms. In this paper, I examine what one needs to be able to give a conceptual explanation of addition and subtraction of multidigit whole numbers in the contexts of the standard algorithms and in other non-base-10 contexts. Does understanding the essential conceptual components of knowledge suffice? Next, I discuss the conceptual components of knowledge needed to explain the algorithms.

In the context of the standard U. S. algorithms, we typically treat the digits in a number as if they represent $1 \mathrm{~s}$. When adding $321+654$, for example, we add $4+1=5,5+2=7$, and $3+6$ $=9$ to get to the answer 975 (see Figure 2a). When the sum is larger than 9 we regroup the digit in the ten's place to the next column. For example when adding $987+655$, we add $7+5=12$. Rather than noting the 12, we put the 2 in the answer column and regroup the 1 to the next column to the left. We repeat this for $5+8+1=14$, considering the regrouped 1 from the previous place, and again for $9+6+1=16$ (see Figure $2 \mathrm{~b}$ ).

\begin{tabular}{rr}
321 & 11 \\
+654 & 987 \\
\hline 975 & +655 \\
\hline 1642
\end{tabular}

Figure 2a. Adding $321+654$ using the standard algorithm for addition.
Figure $2 b$ Adding $987+655$ using the standard algorithm for addition. 
We can treat the columns individually because the relationship between adjacent columns is always a 10:1 relationship. Moving left, the value of a digit is 10 times as great as the previous digit. Thus a 10 in the one's place can be rewritten as a 1 in the ten's place because 10 ones is equivalent to 1 ten. Similarly, a 10 in the ten's place can be rewritten as a 1 in the hundred's place because 10 tens is equivalent to 1 hundred, and so forth. To understand this relationship, a student must see a number in terms of reference units and flexibly change the reference units for a number (123 as 123 ones; or 1 hundred, 2 tens, 3 ones; or 12 tens, 3 ones; or 1 hundred, 1 ten, 13 ones; etc.). Typically in talking about numbers, we do not state reference units explicitly, but the number name implies the referent unit ones (e.g., 123 refers to 123 ones). However, to explain regrouping in the algorithms, we need to (a) see a number digit in terms of its reference units, (b) relate the digits to one another, and (c) know that a number can be regrouped. So the question arises, is the ability to do these three things sufficient to enable one to explain regrouping in the context of the standard algorithms and to decide whether an algorithm is applicable in a given context? Answering that question is the focus of the next two sections.

\section{How to decide when knowledge components are useful}

Focusing on content knowledge (as opposed to such aspects as pedagogical content knowledge), researchers isolated two kinds of knowledge, the knowledge held and the ability to apply that knowledge (e.g. Mason \& Spence, 1999; Weber, 2001), and showed that these knowledge types differ. Weber (2001) showed that "an understanding of mathematical proof and a syntactic knowledge of the facts of a domain are not sufficient for one to be a competent theorem prover" (p. 107) but that strategic knowledge is essential and that "effective problem solvers often possess strategic knowledge (Greeno, 1973), or heuristic guidelines that they can 
use to recall actions that are likely to be useful or to choose which action to apply among several alternatives" (p. 111). Mason and Spence (1999) distinguished knowing-about-comprised of "knowing-that (factual), knowing-how (technique and skills), and knowing-why (having a story in order to structure actions and from which to reconstruct actions)" (p. 135)—-from knowingto- "active knowledge which is present in the moment when it is required" (p. 135). Thus, one's knowing something (or knowing that something is applicable) does not ensure his or her being able to use it. To use knowledge, the student needs to see that it is useful in the given context. Further, the student needs to decide whether a piece of knowledge is applicable - the focus of the next section.

\section{How to decide when the standard algorithms are applicable}

Part of understanding something (e.g., the standard algorithms for addition and subtraction) is recognizing situations in which the knowledge is and is not applicable (cf. adaptive expertise). But how does one decide whether a new context is appropriate for the application of the standard algorithms? Lobato (2006) stated, "A central and enduring goal of education is to provide learning experiences that are useful beyond the specific conditions of initial learning" (p. 431). Thus, when presented with a new situation/condition, the students will need to decide whether what they learned in another situation applies to this new situation/condition as is, whether it may need to be modified, or whether it does not apply at all. From the actor-oriented-transfer perspective, transfer is viewed as "the generalization of learning, which also can be understood as the influence of a learner's prior activities on his or her activity in novel situations" (p. 436). Using this notion of transfer, part of understanding whole numbers and algorithms for addition and subtraction would be to understand why they are 
applicable in certain contexts (i.e., base-10) and whether they (a) are applicable unchanged in new contexts (i.e., non-base-10), (b) need to be modified to apply (i.e., adapted to the new base), or (c) are not applicable at all. Consider a non-base-10 situation. The standard algorithms would not be applicable unchanged because they are built on the base-10 system (with a 1-to-10 trade relationship between adjacent digits). However, one could modify the algorithms if one is aware of the fact that regrouping relies on the underlying base. Rather than regrouping 1 unit for 10 of the next smaller units (in the context of the subtraction algorithm) one could regroup 1 unit for any number of units of the next smaller size in that base and thus modify the algorithm to show that. This study is designed to determine what understanding of number and of the algorithms one needs to (a) realize when an algorithm is applicable and (b) modify a previously learned algorithm to be applicable in a new situation.

Thus, to summarize the previous four sections, the following research questions are addressed in this study:

1. What constitutes conceptual understanding of multidigit whole numbers?

a. Is knowing individual concepts needed to explain regrouping in the context of addition and subtraction sufficient?

b. What role do connections among individual knowledge components play in terms of a conceptual understanding of number?

2. What understanding of number and of the algorithms is needed to determine when the algorithms are applicable (valid and useful) or how to modify a previously learned algorithm to be applicable in a new situation?

\section{Methods}


The data analyzed are drawn from two 75-minute semistructured interviews with 1 of 15 PSTs, at a large, urban, state university. This PST participated in a larger study (Thanheiser, 2009) and was subsequently chosen to serve as the case-study subject for this report. In the larger study, PSTs' conceptions of multidigit whole numbers were examined in the context of addition and subtraction. The choice of this PST, Jamie, for this study was based on the categorization of her conception of number as the incorrect concatenated-digits-plus conception even though she correctly answered some questions. Jamie's conception, concatenated digits plus, was the most commonly held conception in this study (held by 7 of the 15 PSTs) and was a newly identified conception in that study (Thanheiser, 2009). This conception has been identified in subsequent studies to be the most commonly held conception among PSTs entering the elementary mathematics content courses (Thanheiser 2010). One defining characteristic of the concatenated-digits-plus conception is that students give correct answers/explanations some, but not all, of the time. Jamie, a freshman who was fairly explicit about her knowledge, had experience tutoring and believed that her current knowledge was sufficient to teach Grades K-3 (as did 13 of the 15 PSTs in that study). Examining her case provides insight into aspects of the concatenated-digits-plus conception.

Questions for the interviews were developed by a team of researchers, piloted, and then modified. Tasks were planned in advance, but follow-up questions were posed on the basis of the PSTs' responses so that the PSTs' conceptions could emerge in their answers. PSTs were asked to answer questions in the context of the standard algorithms as well as in other contexts. For example, PSTs were asked to explain whether the value of a number stays the same when it is regrouped in the context of the subtraction algorithm. Two sample tasks are provided below (Figures 3 and 4). 
The rationale for the Addition and Subtraction Tasks was to get a good sense of what students knew about whole numbers in those contexts. The rationale for the Train Task was to examine whether the PSTs could recognize when the standard procedure for subtraction (which is built on the base-10 numbers) is applicable.

Each interview was transcribed and analyzed; Interview 1 served as a basis for Interview 2. Using a grounded theoretical approach with open coding, I categorized the PSTs' conceptions of multidigit whole numbers. After all 15 interviews were analyzed, I chose to study further one PST who exhibited various components of knowledge essential to explaining the standard algorithms but still struggled with the explanation. I analyzed this PST's interviews in depth to identify various components of knowledge essential to explaining the standard algorithms and to find instances where explanations broke down. These instances were then analyzed using (a) the conceptual/procedural framework with a focus on connections among knowledge components, (b) the framework for PSTs' conceptions of multidigit whole numbers laid out above, and (c) the notions of transfer and strategic knowledge.

\begin{tabular}{|c|c|c|c|c|}
\hline Addition & ubtract & n Tasks & & \\
\hline $\begin{array}{r}527 \\
-135 \\
\end{array}$ & $\begin{array}{r}708 \\
-253 \\
\end{array}$ & $\begin{array}{r}577 \\
-159 \\
\end{array}$ & $\begin{array}{r}3203 \\
-365 \\
\end{array}$ & $\begin{array}{r}389 \\
+475 \\
\end{array}$ \\
\hline
\end{tabular}

Ask the PSTs to solve $527-135,708-253,577-159,3203-365$, and $389+475$ as a baseline tasks; ask the PSTs to talk aloud while working, or allow the PSTs to finish all tasks and ask the PSTs to explain how they solved them.

\section{Discussion of $527-135$}

After all the tasks have been solved, return to $\mathbf{5 2 7}-\mathbf{1 3 5}$ and ask general questions [depending on the PSTs' answers, I chose from the following questions]:

1. "Can you talk a little bit about what you did here [pointing to $527-135]$ ?"

2. "What are you doing here [pointing to the regrouping within $527-135]$ ? Why does it work?"

3. "What exactly is going on here-in the regrouping part?"

4. "Did you change the value of the 527?"

5. "What do the small numbers mean?" 
6. "Why can we simply cross out a number? How and why does this work?"

7. "We can always cross out the number to the left, make it one smaller, and put a 1 by the number next to it on the right. Can you explain why that [procedure] works?"

8. "What happens if the number to the left [the number to be regrouped] is a zero, as in 3203 365 ?"

9. If the PST struggles with regrouping between hundreds and tens, focus on regrouping tens to the ones: $577-159$ [ or $52-17$ ].

Alternatively to focusing on what the PSTs did, I sometimes presented a hypothetical child's solution (Carl's solution below) and asked about what the child had done. The hypothetical child's solution I presented to the PSTs is the same as most PSTs' solutions.

\section{Discussion of $389+475$}

1. "Solve $389+475$ and talk about the regrouped digits."

2. "Talk about the two 1s."

i. "What does this 1 [regrouped to tens] represent?"

ii. "What does this 1 [regrouped to hundreds] represent?"

iii. "Compare the two 1s. Are they the same or are they different?"

iv. For each regrouped 1, ask, "One what?" Pose this question only as a last resort!

\section{Compare regrouping in addition and subtraction}

1. "In subtraction, you put a 1 next to the digit on the right; in addition you put a 1 on top of the digit to the left. Discuss those two [procedures]. Why are they different?"

Possible follow-up questions to be asked follow:

2. Present $101-2$ and ask, "Can you solve that with the algorithm?"

a. "When you regrouped, did the value of the top number change?"

b. "Why or why not?"

c. "What do the small [point to the small digits] numbers mean?"

d. "Why can we simply cross out a number? How and why does this work?"

3. Present $17-9$ and pose the same questions as were posed above.

Figure 3. Addition and Subtraction Tasks with follow-up questions.

\section{Train Task}

Read this scenario to the PSTs: "Last week the children in a third-grade classroom were given the following problem: You were on a train that left Los Angeles at 2: 53 p.m. and arrived in Phoenix at 7:08 p.m. How long were you on the train?" 
One student solved the problem as follows:

$$
\begin{aligned}
& 7^{6: 1} 08 \\
& -2: 53 \\
& \hline 4: 55
\end{aligned}
$$

Ask the

PSTs

what

they

think

The child explained, "I took the 3 from the 8 ; that is 5 . Then I couldn't take the 5 from the 0 , so I borrowed 1 from the 7 and put it by the zero. Then I took 5 from 10 ; that's 5 . Then I took 2 from 6 , and that's 4."

1. If the PSTs think that the child's solution is correct, ask them to explain. Follow-up questions can be used:

a. Use 9:08 a.m. to 4:25 p.m. for departure and arrival times. Using the algorithm, they will arrive at the answer 4:83, which should put them in conflict. Ask, "Why didn't the algorithm work here?"

b. How long is the time from 8:59 a.m. to 9:08 a.m.?

c. Somebody solved this (2:53 to 7:08) a different way and got 1 hour and 15 minutes, as the answer. What do you think of that?"

Work with the PSTs until they realize that the algorithm does not yield a correct answer in the time context. Then move to the next questions.

2. If the PSTs are aware that the algorithm does not yield a correct answer, ask the following:

a. "Why does the algorithm not work?"

b. "Can you devise a travel-time algorithm that will always work?"

3. Pose the following more specifically focused questions if the PSTs struggle to answer Question 2 or do not answer completely:

a. "What is it about the 60 -minute hour that causes this algorithm not to work?"

b. "How far off will the answer be (always)? Why?"

Figure 4. Train Task with follow-up questions.

\section{Results and Discussion}

The first part of this section focuses on the role connections play in conceptual understanding. More precisely, if a student has all the components of knowledge needed to explain a concept, will that student be able to give a conceptual explanation? The second part focuses on context. What is needed to determine in what context a concept/procedure is applicable? 


\section{Relationship of regrouping with 3-digit numbers to regrouping with 2-digit numbers}

Let us revisit the introductory scenario. A PST explains regrouping in 2-digit numbers. What inferences can one draw? In explaining subtraction for 17 - 9 (see Figure 5a), Jamie said, Instead of 7 ones and 1 ten, I'm making it 17 ones. ... Normally, the ten is all hooked together, and the ones are separate. So if you had 17 separate ones, you could take 9. But if you had 1 ten and 7 ones, you can't take 9 [ones] from it. Jamie explained that she regrouped 1 ten into 10 ones. She flexibly saw 10 as 1 ten and as 10 ones and used that understanding to explain regrouping between tens and ones in the algorithms. When regrouping from ones to tens in the addition algorithm for $389+475$ (see Figure 5 b), Jamie explained, "Well, $9+5=14$. So you leave the 4 in the ones, because that's just a single number. And you have 10 hooked onto it, so you add it into the ten's column." She then explained more explicitly, "You're taking 10 and putting 1 ten in the ten's column."

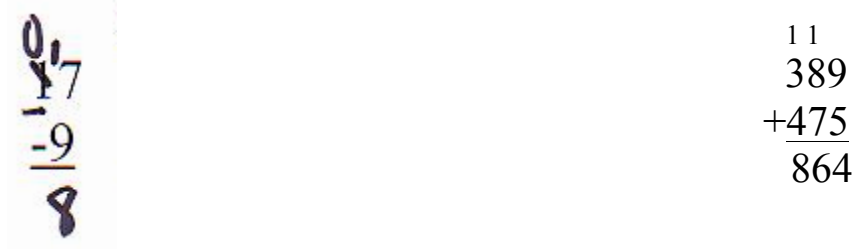

Figure 5 a. Standard subtraction algorithm for $17-9$.
Figure 5b. Standard addition algorithm for 389 +475 .

When considering two-digit numbers, Jamie seemed to see numbers in terms of reference units and could relate those reference units. What inferences can we draw from this ability? Are her understandings well connected? Does she recognize which knowledge components to use in her explanation? At least in this example she seems competent. She seems to understand (a) that each digit represents a different unit type, (b) that we can reconceive of different unit types in terms of each other (i.e., 1 ten is 10 ones), and (c) that we can regroup digits (and values) without 
changing the problem. And it seems that these three components of conceptual knowledge are connected to one another and to the context of the standard algorithms (see Figure 6).

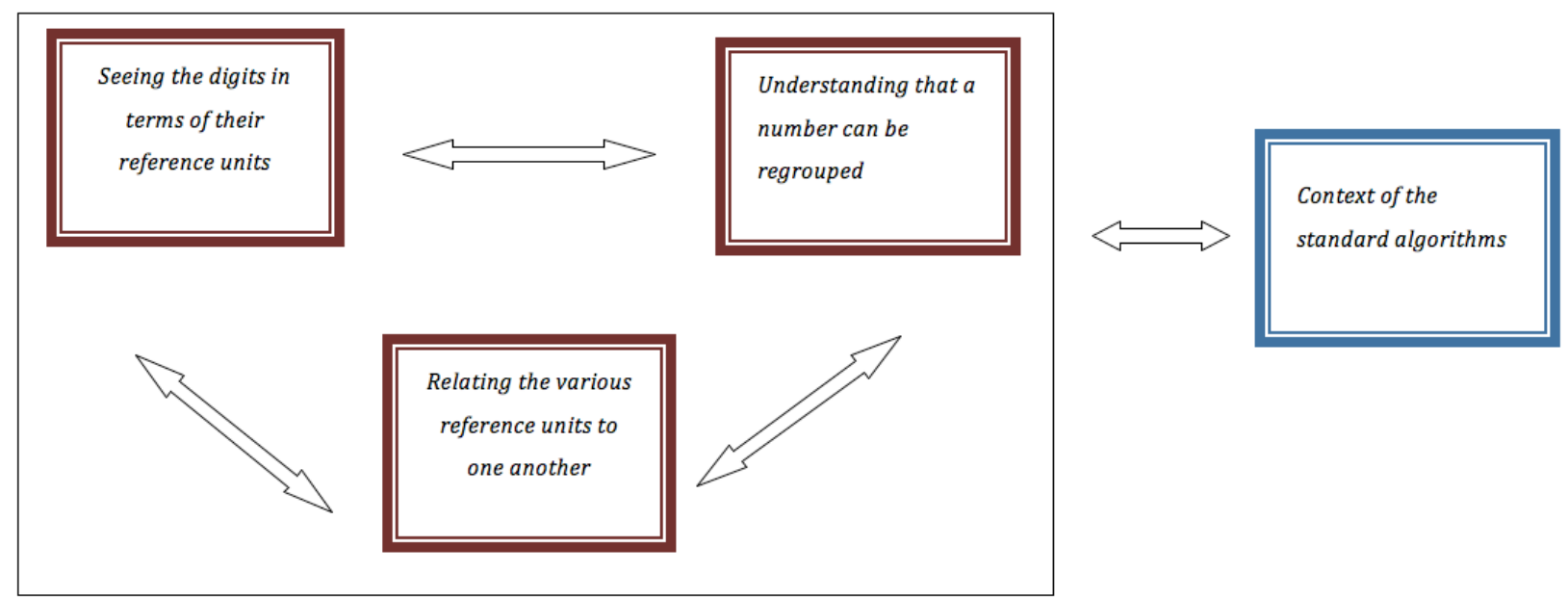

Figure 6. Connection of components of conceptual knowledge to one another (i.e., conceptual understanding) and to the context of the standard algorithm for 2-digit numbers (i.e., strategic knowledge).

For 3-digit numbers, Jamie appropriately labeled the places and discussed the relationships among the place values. She stated, "If you have 10 ones, you have 1 ten [reconceiving 10 ones as 1 ten]. ... If you have 10 tens, then you get 1 hundred [reconceiving 10 tens as 1 hundred]" Thus, she seemed to extend her understanding of the relationship of adjacent reference units from ones and tens to tens and hundreds. She also explained, "One times 10 is 10 ; ten times 10 is $100, \ldots$ so it's going up in those kinds of increments ... so these are always in increments of 10." She noted this relationship going both directions (referring to regrouping in the context of the addition and the subtraction algorithms):

So when you're taking 1 away from here [hundred's place] and you're moving it back a spot, you would take 100, and divide it by 10 . And you'd see how many times 10 goes in $100 \ldots$... Because 100 is 10 tens ... because there's 10 tens in 100 , to see how many you would add here [in the ten's place] ... I'm taking 1 hundred; I'm taking 10 tens. 
At this point she seemed to reconceive 1 hundred in terms of 10 tens and to be aware that numbers can be regrouped.

The selected quotes above provide evidence that Jamie has the conceptual components of knowledge needed to explain regrouping in the context of addition and subtraction (at least for 3digit numbers). She seemed to (a) understand the value of each digit (hundreds, tens, ones), (b) understand the relationships between adjacent digits (10 ones in a ten and 10 tens in a hundred), and (c) think about regrouping between the hundreds and the tens. So, is this understanding sufficient to enable her to explain regrouping in the context of the addition and subtraction algorithms?

Consider whether you are convinced that Jamie understands regrouping in the context of 3-digit numbers. If not, what may be needed in addition?

Jamie struggled explaining regrouping with 3-digit numbers. After multiple unsuccessful attempts to relate the regrouped digits (the 1 "taken" from the hundred's place and the 1 "added" to the ten's place), she was asked to use her reasoning in 2-digit numbers (see above) in the context of $527-131$ (see Figure 7). In the context of 2-digit numbers, Jamie had regrouped 1 ten as 10 ones into the one's place. She had "unhooked" the ten to make it 10 ones.

$$
\begin{array}{r}
{ }^{4} p^{1} 27 \\
-135 \\
\hline 392
\end{array}
$$

Figure 7. Standard subtraction algorithm for $527-135$.

In the context of 3-digit numbers, Jamie did not use reasoning similar to her reasoning in 2-digit numbers but struggled in explaining the values of the digits in the regrouped number. She 
stated, "You can have 100 of ... 500 ones. But I don't know why that [4 remaining in the hundred's place] would be 400, if you're only borrowing 10." In this context (explaining the values of the regrouped number/digits) Jamie did not seem to apply the conceptual knowledge components she exhibited previously (described above) even though she was prompted to do so. She did not reconceive 1 hundred from the hundred's place to be regrouped as 10 tens. Rather she seemed to think of taking a ten (or 10 ones) from the hundred's place and was confused about why the remaining value in the hundred's place would be 400 (rather than 490). But Jamie read the digit 4 in the hundred's place as 400 and the digit 5 in the hundred's place as 500 . Thus she was aware that, in regrouping, the value of the number changed by 100 . However, she read the 10 in the ten's place incorrectly as 10 ones (or 1 ten) and thus struggled to connect the 100 missing from the hundred's place to the 10 she added in the ten's place. The reference unit for the 10 in the ten's column seemed to be ones instead of tens, leading to her confusion when she tried to relate the 100 and the 10 . In this context, she did not correctly see the digits in terms of their reference units and thus struggled to relate them.

When solving $389+475$ (see Figure 5b), Jamie explained regrouping between tens and hundreds as follows: "We've got 6 ones [in the ten's column], and we've got 10 left over. So we add 1 to the 3 [in the hundred's column]." Again she seemed to think in terms of ones for the 10 in the ten's column. When asked to explain the regrouped 1 [in the hundred's column] in more detail, Jamie stated, "It's a ten ... 10 left over from the 6." But Jamie also seemed to think of the 1 as being in the hundred's column and, as such, representing 100 . This view again led to a conflict in relating the 10 [regrouped from the previous place] to the 100 .

Jamie explained that she could see the connection between the one's and ten's places but not between the ten's and hundred's places: "Just like how you have ones and tens and hundreds, 
this [the relationship between ones and tens - in the box; see Figure 8] is 10, clearly. This [the relationship between tens and hundreds - points to the line between 10 and 100] is where it gets a little confusing to me, because it's not just $1+10 . "$

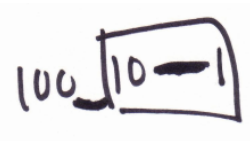

Figure 8. Jamie's analysis of the site of her confusion.

I explain Jamie's confusion as follows: Jamie did not generalize from the ten's/one's relationship to the adjacent powers-of-ten's relationship. For explaining regrouping from ones to tens, ones is the appropriate reference unit for the regrouped 10, but for explaining regrouping from tens to hundreds, ones is not the appropriate reference unit for the regrouped 10. Instead, the appropriate reference unit is tens. Even though Jamie seemed to realize that the digit in the ten's place represents tens sometimes, she sometimes seemed to see this ten's digit as representing ones.

So what is missing in Jamie's understanding? Jamie exhibited all three components of number shown in Figure 6 at least some of the time. She saw the digits in terms of their reference units (sometimes), she knew that a number can be regrouped, and she was able to relate various reference units (some of the time). So why was she unable to explain regrouping in 3-digit numbers?

In regrouping 3-digit numbers, Jamie did not seem to use the same concepts she used to explain regrouping with 2-digit numbers. She did not correctly conceive of all digits in terms of their reference units (that concept was weak in this context), and thus she struggled to relate the 
values of the hundred's and ten's digits to each other (that concept was weak in this context).

That is, she failed to see digits in terms of their correct reference units at times, so the connections between the various concepts needed to explain regrouping were weak at best. Jamie seemed to be able to relate adjacent reference units to each other in contexts other than the standard algorithm (as described above). However, even after being prompted to use reasoning similar to that used in the context of 2-digit numbers, Jamie struggled with this explanation. Thus the connection between the context of the standard algorithms and the concepts needed to explain it were also weak at best (see Figure 9).

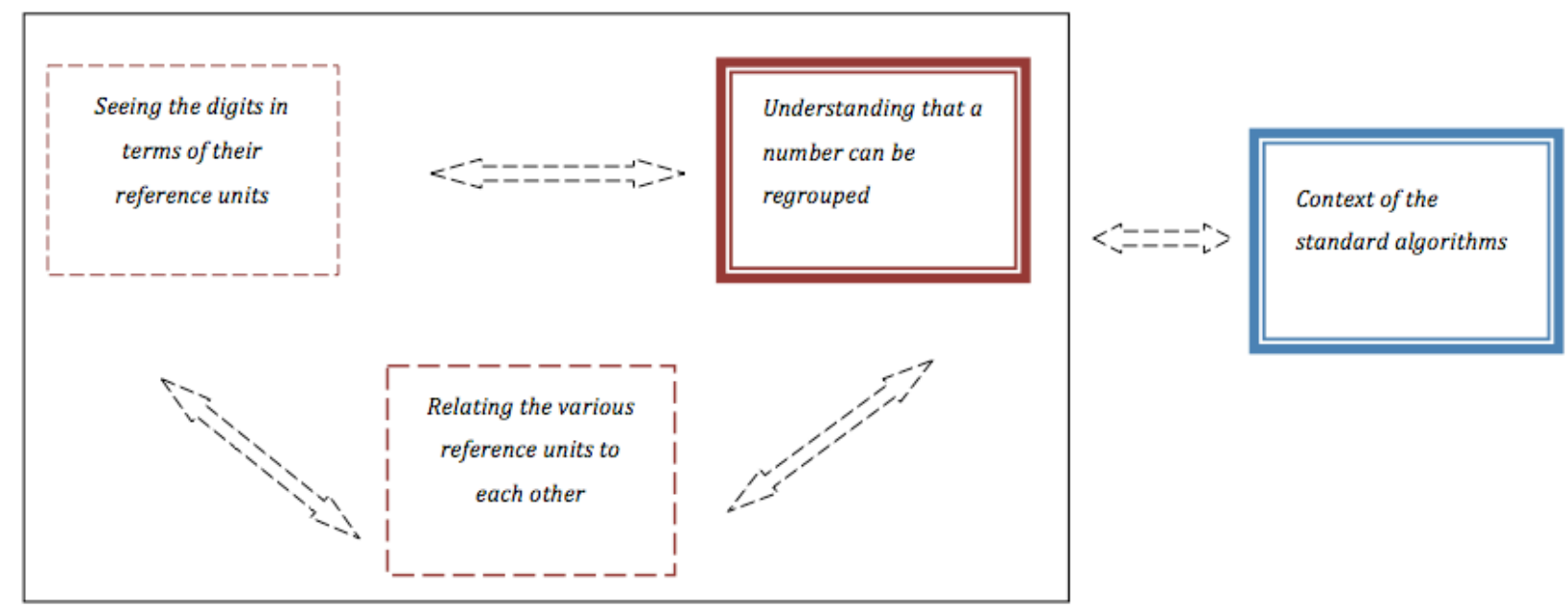

Figure 9. Weak or no connection among components of conceptual knowledge for 3-digit numbers and between concepts and the context of the standard algorithms.

Jamie's knowledge of regrouping in the context of 3-digit numbers cannot be described as deep conceptual knowledge; she seemed to (a) hold some weak conceptual knowledge components, (b) have some weakly connected components of conceptual knowledge (weakly connected to the context and to one another), and (c) lack the knowledge to apply knowledge components that were available in other contexts even after being prompted to use reasoning similar to her reasoning with 2-digit numbers. Thus her knowledge of regrouping 3-digit 
numbers in the context of the standard algorithms at this point may be characterized as superficial conceptual knowledge "unconnected, disembodied, meaningless, context-bound, or mechanical" (Baroody et al., 2007, p. 117).

This example illustrates the clear conceptual gap between 2-digit and 3-digit numbers. Students can exhibit well-connected knowledge in the context of 2-digit numbers and be able to apply that knowledge in the context of the standard algorithms but struggle when asked to explain regrouping in the context of the standard algorithms with 3-digit numbers. This problem may be due in part to the change in reference units that is required when moving beyond tens and ones. Tens and ones can always be related to ones: Regrouping 1 ten to the one's places makes it 10 with the reference unit ones. Regrouping 10 ones into the ten's place make it a 1 in the ten's place, and thus easily connectable to 10 . But in relating tens and hundreds (or other units), we no longer have this relationship (the issue Jamie illustrates in Figure 8). Now students need to explicitly change the reference units of the larger unit to 10 of the smaller when subtracting (or vice versa when adding).

When introducing regrouping, teachers typically explain regrouping in 2-digit numbers in depth, but when introducing regrouping in larger numbers, they focus on the individual columns (i.e., they treat each adjacent pair of digits in multidigit numbers as separate 2-digit numbers within the larger number). Students often begin to apply an algorithm by operating on the ones (and if necessary regroup the ones to or from the tens). They next cover the one's column and ignore it. They then treat the next two columns (tens and hundreds) as if they were ones and tens. This practice yields correct answers because of the underlying structure of powers of ten; the students, however, are often unaware of this fact. In a study of 27 PSTs' conceptions of whole number (Thanheiser; under review), 6 PSTs used this strategy when asked to explain regrouping 
in subtracting $527-135$. After subtracting the digits in the one's column, they covered the one's column and regarded the remaining problem as $52-13$ (see Figure 10, Step 2), a 2-digit subtraction problem in which they considered the regrouped digit as 10 (See Figure 10, Step 3). When asked to explain the regrouping without covering the ones, a PST gave this typical response: "I don't really know how I would explain it .... 'Cause now I don't know how to explain it without this [one's column] being taken away."

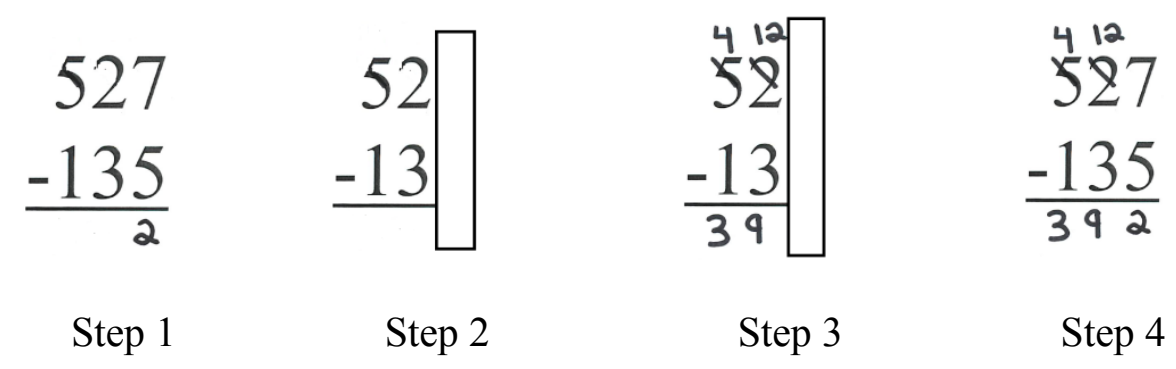

Figure 10. One PST's work on $527-135$, beginning with the ones.

Although students may understand the ten-to-one relationship between tens and ones (either procedurally or conceptually), they may focus on only this relationship and apply it iteratively by covering successive columns when they perform the algorithms with larger numbers. Such students could not explain why the 10:1 relationship holds for all adjacent place values. Jamie's case illustrates the need, ideally before the algorithms are introduced, to examine extensively both the underlying structure of the base-ten system and the reason one can treat adjacent digits as if they were 2-digit numbers. Pesek and Kirshner (2000) showed the harm of focusing on procedures only or focusing on procedures before concepts; Jamie's case further highlights that students who become comfortable with the procedures for adding and subtracting may use those without understanding why they can be applied. 
This case also illustrates that knowing the individual components necessary to explain regrouping with 3-digit numbers and successfully applying an algorithm is insufficient. A student may know the requisite individual components to explain a concept but may be unable (i.e., lack the strategic knowledge) to do so. In our classrooms, we must do more than focus on the various aspects (knowledge components) required for a concept; we need to emphasize the connections among the knowledge components and the contexts in which they apply. To teach effectively, thus, requires both a focus on conceptual knowledge (knowledge-about) and strategic knowledge (knowledge-to).

Researchers have shown that PSTs struggle in explaining regrouping in the context of 3digit numbers (Ball, 1988; Ma, 1999; Thanheiser, 2009, 2010) and have explicated the conceptions PSTs bring to their mathematics classes for elementary school teacher (Thanheiser, 2009, 2010). This study adds to the current literature:

(1) It provides a better understanding of the complexity of multidigit whole numbers, especially the conceptual gap between understanding 2-digit and 3-digit numbers. Multidigit whole numbers are often dismissed as a simple concept with the reigning hypothesis that "if you just ask them to explain" or "if you just point out that this is 10 [or 100, or 1000, etc.]," they will be able to explain. This case clearly illustrates the contrary. Even a student who seemed to have all the knowledge components necessary to explain regrouping was unable to do so.

(2) An understanding that strategic knowledge is essential in addition to conceptual knowledge and is a necessary focus in teaching and learning. In addition to addressing the conceptual-knowledge components underlying a concept, teachers also need to focus on (a) the connections among those knowledge components (conceptual knowledge) and (b) connections between the knowledge components and a context (strategic knowledge). 


\section{What does one need to decide when an algorithm is applicable?}

When needing to decide whether an algorithm is applicable in a situation, how would PSTs make that decision? Previous research has shown that PSTs can typically apply the algorithms for addition and subtraction; however, in these studies, the algorithms were applicable to the contexts given - all base-10. Thus an unanswered question is whether PSTs would recognize in what context an algorithm is applicable and be able to modify the algorithm to make it applicable if possible. Knowledge of a concept/method includes (a) a deep connected conceptual understanding of it and (b) being able to draw on that knowledge in the appropriate situations (when it is useful) and decide whether it can be applied as is or needs to be modified.

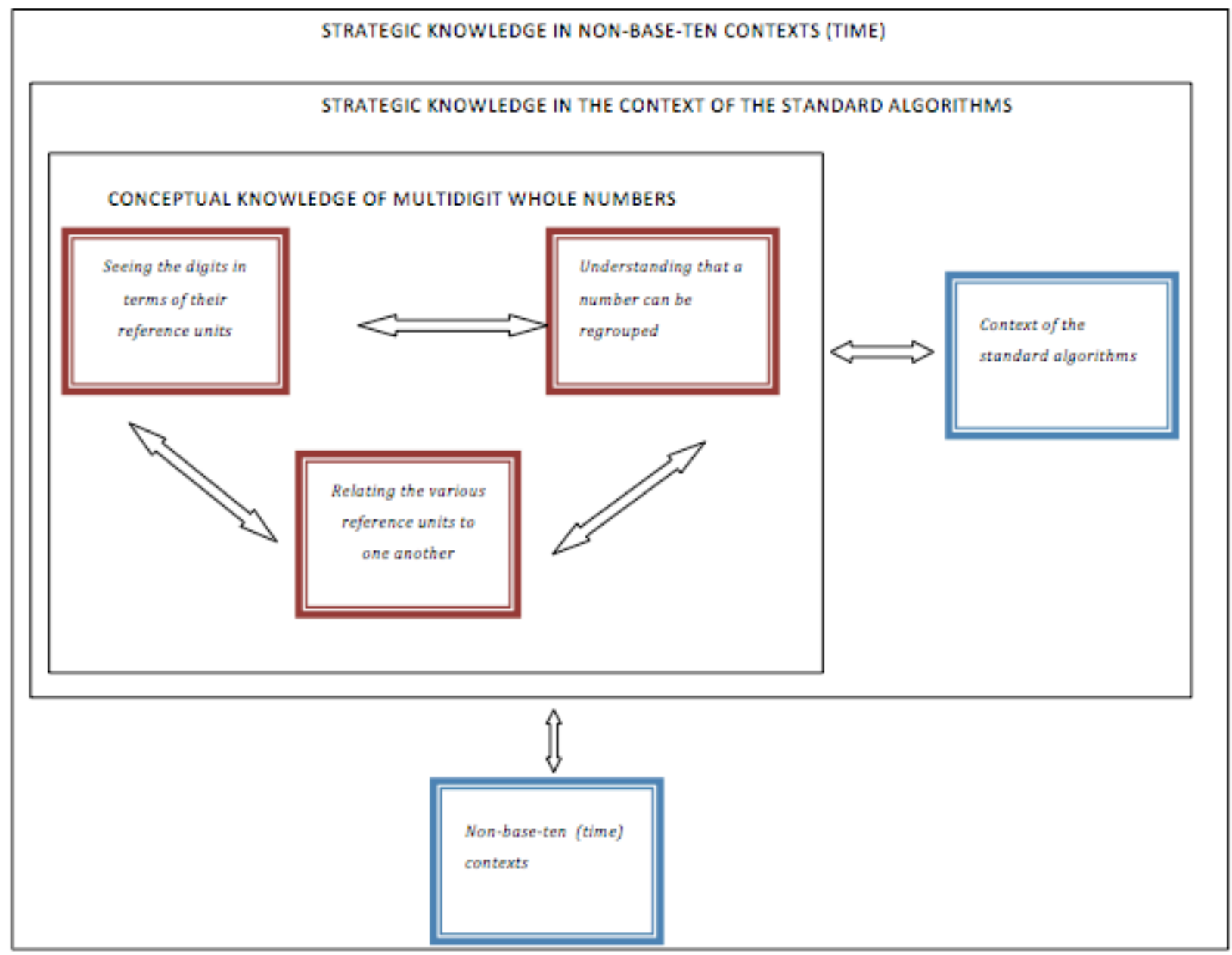


Figure 11. Relationship of conceptual knowledge and strategic knowledge at 2 levels.

Figure 11 illustrates the nested layers of strategic knowledge for the time context in the Train Task shown in Figure 4. On the first level, the students need to know to apply their knowledge components in the context of the standard algorithms; on the second level, they need to recognize the applicability of the standard algorithms and possibly make modifications. Can PSTs draw on their understandings of regrouping numbers in the context of standard algorithms? Do PSTs recognize when algorithms are applicable, and can they, if necessary, modify their knowledge to apply it appropriately in the new context? The answer to the second question is the focus of this section.

Part of understanding the standard algorithms for addition and subtraction is realizing that they are applicable (without modification) only in a base-10 context. To examine whether PSTs consider the context when working with algorithms, I posed the train task (see Figure 4), for which a child incorrectly applied the standard algorithm for subtraction in a context in which it does not apply (not base-10).

In the larger study (Thanheiser, 2009, 2010), 9 of 15 PSTs initially thought that the algorithm applied in the time context, and although 8 of those 9 eventually (after calculating the correct answer in a different way) realized their errors, one PST thought that the child might be correct - even after determining the correct answer by using an alternative method. Thus, 14 of the 15 PSTs recognized the child's answer as incorrect at some point, and although 13 of those 14 PSTs mentioned that 60 minutes make an hour, only 8 of the 13 explained both the mistake the child made (in regrouping 100 instead of 60) and a way to alter the algorithm (i.e., regroup 60 instead of 100) to make it applicable in a time situation. 
Jamie initially thought that the standard subtraction algorithm was applicable in a time situation: "It [the child's application of the standard subtraction algorithm in the time situation] is right; $\ldots$ the time between there [2:53 p.m. and 7:08 p.m.] would be this [pointing to the child's solution of 4:55]." Jamie did not attend to the context (time, not base-10) in which the algorithm was applied. After being told that the child's answer (4:55) was incorrect and working out the correct answer (4:15) to the time problem with the interviewer, ${ }^{2}$ Jamie initially was unable to determine why applying the algorithm was problematic. She said, "The math [in the algorithm] is right." Her understanding of the algorithm's relationship to base-10 numbers was insufficient to enable her to recognize when it could and could not be applied. In addition her trust in the algorithm was strong. It has always yielded correct answers and it had been executed correctly, so what was incorrect about the solution was unclear to Jamie.

To recognize the child's error in this misapplication of the subtraction algorithm in a time context, regrouping 1 hour into 100 minutes, Jamie would need to recognize that the 1 hour should be regrouped into 60 minutes. When confronted with the fact that application of the algorithm had yielded an incorrect answer, Jamie realized, “Oh, because this [digit in the hour's place] is 60 minutes." She explained that the digit in the hour's place and the digit in the ten's place of the minutes are "60 apart." She then correctly explained that to alter the algorithm for a time context, she should regroup 60 minutes: "So we're going to take 60 minutes from here [hours]; ... so we are going to have 68 minutes over here [minutes]." Through this explanation, Jamie shows understanding of the hour's digit in terms of the appropriate reference units (hours), and she regroups it correctly as 60 minutes.

Although Jamie ultimately corrected the algorithm for use in the time context, her interpretation of the child's work stemmed from her own misunderstanding of the mathematics

\footnotetext{
${ }^{2}$ By counting up from 2:53 p.m. to 7:08 p.m.
} 
of the standard algorithm. She did not see the child's error as regrouping 1 hour into 100 minutes ( 10 in the ten's place of the minutes) because she thought that the child had regrouped 10 ones instead of 100 ones or 10 tens: "He borrowed only 10, and he should have borrowed 60." She explained that the child's regrouping had resulted in 6 hours and "18 minutes." This misinterpretation of the child's solution is consistent with Jamie's conception of number in the context of the standard algorithms, wherein she had read the regrouped 10 in the ten's place as 10 ones instead of as 10 tens or 100 ones. Jamie's recognition of the child's error of incorrectly regrouping 100 minutes resulted not from reflection on the standard subtraction algorithm but instead from her comparing the child's answer to the correct answer. She recognized that the child had regrouped 100 minutes, not 10 minutes, only when she was asked into how many minutes the child had converted in regrouping the hour. In comparing the child's answer and the correct answer, she said,

He got a larger number than I did. So it [the incorrectly regrouped time in the minute's place] would have been 108 minutes [not the 18 minutes Jamie had assumed]; ... [he converted the 1 hour into] 100; he added 100 instead of $60 \ldots$. [and that is incorrect] ... because there is only 60 minutes in 1 hour, and not 100 .

Jamie recognized the child's mistake because in recognizing that the child's answer was larger than hers, she realized that the child's regrouped number must have been larger than hers as well. Even then, she did not seem to recognize the origin of the child's mistake of overgeneralizing the base-10 algorithm to a time context. To do so would require her understanding that 100 ones (or 10 tens) are regrouped from the hundreds to the tens and thus that the ten's place of the regrouped number has 100 ones (or 10 tens).

In summary, Jamie initially failed to recognize that the base-ten algorithm could not be applied in a time situation, indicating that she did not have the strategic knowledge to decide when the standard algorithms are applicable and when they are not. After prompting, Jamie came 
to recognize that the algorithm was not applicable but did not seem to completely understand the source of the problem, indicating a weak connection between her conceptual understanding of multidigit whole numbers and the standard algorithm. She thought initially that the child incorrectly regrouped the 1 (hour) as 10 (instead of 100) minutes, which is consistent with a concatenated-digits-plus conception. After my explicit prompting ("How many minutes did the child convert the hour into?"), Jamie was able to explain the child's mistake; she did not, however, seem to relate the mistake to an overgeneralization of the algorithm.

Researchers have examined PSTs' (i.e. Thanheiser, 2009, 2010) and children's conceptions (i.e. Fuson, 1990; Fuson et al., 1997; Kamii, 1986; Ross, 1990b; Steffe \& Cobb, 1988) of multidigit whole numbers. These studies, however, were conducted in base-10 contexts, and thus issues of applicability and usefulness were irrelevant. Although many curricula for PSTs (for example: Bassarear, 2008; Bennett \& Nelson, 2007) include work with different number systems (i.e., Egyptian, Mayan, Babylonian, etc.) and different bases, they do so to help PSTs learn about and reflect on the base-10 number system rather than to consider algorithm applicability. In contrast to the current literature, this study adds (a) examination of a new question, namely the applicability and usefulness of the algorithms, and (b) the illustration of familiar contexts such as time and measurement (mixed base), which do not require the extra time of introducing different bases or number systems, to examine applicability and usefulness.

In a typical classroom, teachers rarely consider the limits of the applicability of algorithms. Students learn to add, subtract, multiply, and divide numbers without emphasis on when the algorithms are applicable and why they are or are not applicable in certain contexts. Using a time context (or other non-base-10 contexts familiar to the students, such as length measurements, etc.), a teacher can help students better understand the standard algorithms by 
introducing boundaries of their applications . Using non-base-10 contexts highlights the characteristics of the base-10 context without introducing other bases and enables students to move beyond knowledge-about and incorporate knowledge-to or strategic knowledge. In simpler terms, to know something includes knowing when it is and is not applicable.

\section{Conclusions and Implications}

When reading Jamie's responses presented at the beginning of this report, one reasons that Jamie has the knowledge components essential to explaining regrouping with 3-digit numbers in the context the standard algorithms. A closer examination of her responses across the two tasks detailed in this report highlights that even though she seems to have the knowledge components needed to explain such regrouping, she struggles to do so. Her struggles may be due to weakly held conceptual knowledge: (a) weakly held conceptions in the context of 3-digit numbers (see the boxes Figure 9), or (b) weakly held connections among the knowledge components (see connection between the boxes in Figure 9). The struggles may be due to weak strategic knowledge: (a) the weak connection between the context of the algorithms and the knowledge components or (b) the weak connection between knowledge in the context of the standard algorithms and other (non-base-10) contexts. Or the problem may be a combination of these factors.

When teaching standard algorithms for operating on multidigit numbers, we instructors need to (a) move beyond a focus on 2-digit numbers because of the clear conceptual gap between 2-digit and 3-digit or larger numbers, (b) emphasize the connections among the various concepts needed to make sense of regrouping, and (c) clarify the contexts in which regrouping is and is not applicable and the factors that determine applicability. Thus a focus on both conceptual and 
strategic knowledge is essential. Students should explore reference units for digits beyond the tens and focus on the relationships among the various reference units as well as on the relationships between the units and the context (strategic knowledge).

Focusing on strategic knowledge could include attention to connections of conceptual knowledge to why the procedures yield correct answers and why the procedures apply in certain contexts. Children and preservice teachers need opportunities to push the boundaries of applicability. In addition to working in base-10 contexts, children and preservice teachers benefit from work in non-base 10 contexts. Such work in familiar contexts like time and measurement does not necessitate the introduction of abstract systems in bases other than 10 .

Another way to focus on strategic knowledge could be allowing students to relate unit types in various settings (such as base-10 blocks, money, etc.) and connect those to whole numbers and regrouping, thus strengthening the connections. Students can often relate unit types in individual contexts (such as base-10 blocks) but not connect that knowledge to the context of the standard algorithms. We need to focus more on connections and sense-making activities in work with whole numbers and algorithms.

In summary, even if a student exhibits what seems to be adaptive expertise in the context of 2-digit numbers and seems to have all the knowledge components necessary to explain regrouping in the context of 3-digit numbers, that student may be unable to give a conceptually based, correct explanation. Thus, as teachers, we must push beyond teaching individual knowledge components and ensure that connections among knowledge piece are explored. In addition, we need to emphasize the role of the context and explicate what aspects of the context (in this case base-10) determine the algorithms' applicability. To know something well (in this case the algorithms) includes understanding when it is and is not applicable. 


\section{References}

Ball, D. L. (1988). Knowledge and reasoning in mathematical pedagogy: Examining what prospective teachers bring to teacher education (Doctoral dissertation, 1988). 50 doctoral dissertation, Michigan State University, Ann Arbor. (02)

Baroody, A. J., Feil, Y., \& Johnson, A. R. (2007). Research Commentary: An Alternative Reconceptualization of Procedural and Conceptual Knowledge. Journal for Research in Mathematics Education, 38(2), 115-131.

Bassarear, T. (2008). Mathematics for elementary school teachers. Belmont, CA: Cengage Learning.

Bennett, A. B., \& Nelson, L. T. (2007). Mathematics for elementary teachers: A conceptual approach. Boston, MA: McGraw Hill.

Cobb, P., \& Wheatley, G. (1988). Children's initial understandings of ten. Focus on Learning Problems in Mathematics, 10(3), 1-28.

Fuson, K. C. (1990). Conceptual structures for multidigit numbers: Implications for learning and teaching multidigit addition, subtraction, and place value. Cognition and Instruction, 7, 343-403.

Fuson, K. C., Wearne, D., Hiebert, J. C., Murray, H. G., Human, P. G., Olivier, A. I., . . . Fennema, E. (1997). Children's conceptual structures for multidigit numbers and methods of multidigit addition and subtraction. Journal for Research in Mathematics Education, 28, 130-162.

Graeber, A. O. (1999). Forms of Knowing Mathematics: What Preservice Teachers Should Learn. Educational Studies in Mathematics, 38(3), 189-208.

Graeber, A. O., Tirosh, D., \& Glover, R. (1989). Preservice teachers' misconceptions in solving verbal problems in multiplication and division. Journal for Research in Mathematics Education, 20(1), 95-102.

Hatano, G. (1988). Social and motivational bases for mathematical understanding. In G. B. Saxe \& M. Gearhart (Eds.), Children's mathematics. San Francisco, CA: Jossey-Bass.

Hatano, G. (2003). Foreword. In A. j. Baroody \& A. Dowker (Eds.), The development of arithmetic concepts and skills: Constructing adaptive expertise (pp. xi-xiii). Mahwah, NJ: Erlbaum.

Hiebert, J., \& Lefevre, P. (1986). Conceptual and procedural knowledge in mathematics: An Introductory Analysis. In J. Hiebert (Ed.), Conceptual and procedural knowledge: The case of mathematics (pp. 1 - 27). Hillsdale, NJ: Erlbaum.

Hill, H. C., Ball, D. L., \& Schilling, S. G. (2008). Unpacking Pedagogical Content Knowledge: Conceptualizing and Measuring Teachers' Topic-Specific Knowledge of Students. Journal for Research in Mathematics Education, 39(4), 372-400.

Hill, H. C., Rowan, B., \& Ball, D. L. (2005). Effects of teachers' mathematical knowledge for teaching on student achievement. American Educational Research Journal, 42(2), 371 406.

Huang, T. W., Liu, S. T., \& Lin, C. Y. . (2009). Preservice teachers' mathematical knowledge of fractions Research in Higher Education Journal. http://www.aabri.com/manuscripts/09253.pdf. 
Kamii, C. (1986). Place value: An explanation of its difficulty and educational implications for the primary grades. Journal of Research in Childhood Education, 1(2), 75-86.

Kouba, V. L., \& Wearne, D. (2000). Whole number properties and operations. In E. A. Silver \& P. A. Kenney (Eds.), Results from the seventh mathematics assessment of the national assessment of educational progress (pp. 141-162). Reston, VA: National Council of Teachers of Mathematics.

Lobato, J. (2006). Alternative perspectives on the transfer of learning: History, issues, and challenges for future reserach. The Journal for the Learning Sciences, 15(4), 431-449.

Luo, F. (2009). Evaluating the effectiveness and insights of pre-service elementary teachers' abilities to construct word problems for fraction. Journal of Mathematics Education, 2(83-98).

Ma, L. (1999). Knowing and teaching elementary mathematics: Teachers' understanding of fundamental mathematics in China and the United States. Mahwah, NJ: Erlbaum.

Mason, J., \& Spence, M. (1999). Beyond Mere Knowledge of Mathematics: The Importance of Knowing-To Act in the Moment. Educational Studies in Mathematics, 38(1-3), 135-161.

McClain, K. (2003). Supporting Preservice Teachers' Understanding of Place Value and Multidigit Arithmetic. Mathematical Thinking and Learning, 5(4), 281-306.

National Research Council. (2001). Knowing and learning mathematics for teaching: Proceedings of a workshop. Washington DC: National Academy Press.

Pesek, D. D., \& Kirshner, D. (2000). Interference of instrumental instruction in subsequent relational learning. Journal for Research in Mathematics Education, 31, 524-540.

Ross, S. H. (1990a). Children's acquisition of place-value numeration concepts: The roles of cognitive development and instruction. Focus on Learning Problems in Mathematics, 12, $1-17$.

Ross, S. H. (1990b). Children's acquisition of place-value numeration concepts: The roles of cognitive development and instruction. Focus on Learning Problems in Mathematics, 12, $1-17$.

Shulman, L. S. (1986). Those who understand: Knowledge growth in teaching. Educational Researcher, 15(2), 4-14.

Silverman, J., \& Thompson, P. (2008). Toward a framework for the development of mathematical knowledge for teaching. Journal of Mathematics Teacher Education, 11(6), 499-511. doi: 10.1007/s10857-008-9089-5

Skemp, R. R. (1978). Relational understanding and instrumental understanding. Arithmetic Teacher, 26, 9-15.

Southwell, B., \& Penglase, M. (2005). Mathematical knowledge of pre-service primary teachers Vol. 4. H. L. Chick \& J. L. Vincent (Eds.), International Group for the Psychology of Mathematics Education (pp. 209-216).

Star, J. R. (2005). Research Commentary: Reconceptualizing Procedural Knowledge. Journal for Research in Mathematics Education, 36(5), 404-411.

Steffe, L., \& Cobb, P. (1988). Construction of arithmetical meanings and strategies. New York, NY: Springer-Verlag.

Thanheiser, E. (2009). Preservice elementary school teachers' conceptions of multidigit whole numbers. Journal for Research in Mathematics Education, 40(3), 251 - 281.

Thanheiser, E. (2010). Investigating further preservice teachers' conceptions of multidigit whole numbers: refining a framework. Educational Studies in Mathematics, 75(3), 241-251. 
Thanheiser, E. (under review). Developing preservice elementary teachers conceptions with well-designed tasks: explaining successes and analyzing conceptual difficulties. Journal of Mathematics Teacher Education.

Thompson, A. G., Philipp, R. A., Thompson, P. W., \& Boyd, B. A. (1994). Calculational and conceptual orientations in teaching mathematics. In D. B. Aichele \& A. F. Coxford (Eds.), Professional development for teachers of mathematics (pp. 79-92). Reston, VA: National Council of Teachers of Mathematics.

Tirosh, D., \& Graeber, A. O. (1989). Preservice Elementary Teachers' Explicit Beliefs about Multiplication and Division. Educational Studies in Mathematics, 20(1), 79-96.

Weber, K. (2001). Student difficulties in constructing proofs: The need for strategic knowledge. Educational Studies in Mathematics, 48, 101 - 119. 